Published in "Current Opinion in Psychology", 2018, vol. 23, pp. 20-25, which should be cited to refer to this work.

DOI : $10.1016 / j . c o p s y c .2017 .11 .005$

\title{
Shared Identity in Organizational Stress and Change
}

\author{
Rolf van Dick ${ }^{1}$, Valeria Ciampa ${ }^{2}$, and Shuang Liang ${ }^{3}$
}

Paper in press at Current Opinion in Psychology

\author{
Affiliations \\ ${ }^{1}$ Department of Psychology, Goethe University Frankfurt and Work Research Institute (AFI), \\ Oslo, Norway \\ ${ }^{2}$ Department of Psychology and Cognitive Science, University of Trento \\ ${ }^{3}$ Department of Psychology, University of Zurich, Switzerland and School of Management \\ and Engineering, University of Applied Sciences and Arts Western Switzerland
}

Corresponding author: Rolf van Dick (van.dick@psych.uni-frankfurt.de)

\begin{abstract}
The social identity approach has been found very useful for the understanding of a range of phenomena within and across organizations. It has been applied in particular to analyze employees' stress and well-being at work and their reactions to organizational change. In this paper, we argue that there is a mismatch between the theoretical notion of shared identities in teams and organizations and empirical research, which largely focuses on the individual employee's identification with his or her social categories at work. We briefly review the literature in the two areas of stress and change and conclude with an agenda for future research.
\end{abstract}




\section{Introduction}

Almost every textbook of organizational behavior or work and organizational psychology contains chapters on change in organizations and on workplace stress and health and often these two topics are combined into a single chapter [1] as they are naturally intertwined. Organizational change often leads to employees experiencing more stress but sometimes, change is executed to improve working conditions and to relieve employees from stress. The social identity approach has been used for over four decades now to help explain phenomena within organizational life such as employee satisfaction, motivation and performance, or effective and teamwork [2*, 3]. In this paper, we argue that there is a mismatch between social identity theory and empirical research. Whereas the theory focuses on the power of shared identities in groups, most of empirical research has been conducted on the individual level and considered employees' degree of organizational (or team) identification as a predictor for a range of outcomes. We will thus distinguish between individuals' identification with their organizations versus the sharedness of an organizational identity within the organization. Both identification and identity, however, help satisfy employees' need for experiencing shared realities [4]. Below, we will start with a short overview of the key propositions of the social identity approach. We will then briefly review the existing evidence for employees' identity and identification contributing to their health and how they respond to organizational change. We will conclude this review with directions for future research.

\section{The social identity approach}

The social identity approach comprises social identity theory and self-categorization theory, which have been developed to understand intergroup phenomena such as prejudice and 
discrimination [5]. The theory development started with findings of the so-called minimal group studies in which boys were categorized into two groups based on arbitrary criteria [6]. The boys consistently showed preferential treatment of members of their ingroup in comparison to members of the outgroup even without knowing any of the other individuals and without personally benefiting from such behavior. In developing social identity theory, Tajfel and colleagues argued that we partly derive our self-esteem from personal characteristics such as strengths and weaknesses, personality, individual accomplishments etc. - which is our personal identity. We also, however, derive large parts of our self-esteem from our membership in social groups - our social identity. Tajfel and colleagues proposed that for individuals to achieve or maintain high self-esteem they aim at being associated with high status groups and try to positively differentiate their ingroups from relevant outgroups [7]. Turner and colleagues then developed self-categorization theory to specify the conditions under which group membership becomes salient, i.e. when and how it guides the individual's thinking, feeling, and behavior [8,9]. Both theories together are referred to as the social identity approach (SIA).

The SIA's key assumptions are that behavior based on the individual's personal identity is qualitatively different from behavior guided by one's social identity. If a specific social identity is salient (e.g., because there is a conflict over resources between two departments in an organization), group members will see themselves more similar to each other (employees of the marketing department will see each other more alike than they actually are) while at the same time exaggerating differences between groups (marketing people will see their colleagues from the sales team as all being very different from them). Furthermore, ingroup members will orient their behavior on the norms of the salient group and they will coordinate their behaviors to achieve the group goals.

From a theoretical perspective this should mean that whenever such a shared identity is salient, individuals should provide more support to each other (as fellow ingroup members) 
and perceive a higher sense of collective self-efficacy, which both should reduce stress and strain $[10,11,12]$. Furthermore, strongly identified employees should see those organization's goals that require changes in structure or processes more as their own goals and support the change more - but on the other hand, they may also show more resistance to such change as it may be perceived as a threat to the organization's identity [13]. As we will see below, these propositions have been empirically addressed in a number of studies. However, most studies have looked at the issues not from a shared identity perspective but from the point of the individual employee's degree of identification.

\section{Identity and Stress in Organizations}

Studies over the past two decades have provided important insights on the relationship between individuals' social identifications and psychological well-being [14*]. Specifically, this research has shown how individual's social group memberships have important implications for stress and burnout $\left[15^{*}, 16\right]$. However, most research in organizations focuses on an assessment of individuals' team or organizational identification, rather than an assessment of shared social identities [14], and there is little published data on this. We thus need to draw inferences from research in the laboratory or settings outside of the work domain. Previous research findings exploring shared identity and stress, for example, have shown that when a sense of shared social identity becomes salient, neuroendocrine stress reactions are reduced. Two experimental studies on social-evaluative threats revealed that participants in a personal identity condition had higher salivary cortisol concentrations than participants in a social identity condition, indicating that social identity salience attenuated the stress-induced cortisol reactions [17, 18].

Related findings emerge from the BBC Prison Study [19*, 20], which focuses on shared social identity and stress among prisoners and guards in a prison-like setting. More specifically, guards' levels of burnout, depression, and stress-induced cortisol increased 
because they failed to develop a sense of shared social identity [19]. Conversely, prisoners' levels of burnout, depression, and stress-induced cortisol remained stable, because they developed a sense of shared social identity and collectively resisted the stressors they faced [19].

The importance of shared identities was also demonstrated in a longitudinal study in the religious domain showing that perceptions of a shared identity with other participants at a mass gathering predicted better self-reported indicators of health, and this effect was mediated by the belief of having closer relations with fellow participants to the shared event [21*].

Consistent with quantitative approaches, a qualitative study conducted in real-life settings showed the positive impact of shared identities in dealing with stressful intergroup situations [22*]. More specifically, when new residents transitioned to mixed communities, intergroup anxiety mostly characterized people's experiences coming from 'single identity' areas, but when existing residents offered help facilitating a sharedness of a new identity, the intergroup threats were faced with more resilience [22]. Conversely, isolation and fear characterized the experiences of people who did not adopt a shared identity with the mixed community [22].

Indirect evidence that a shared identity matters comes from a recent meta-analysis that looked at the relations between organizational identification and employee health and moderators of this link [14]. As expected, for higher levels of sharedness in identification operationalized as lower standard deviations of individual identification on an organizational level - the social identification-health relationship became more pronounced, indicating that sharing group identities allows people to benefit more from resources within the group [14].

Finally, a shared social identity regarding job stress management was found relevant for a shared participation in occupational stress management courses [23]. This study provides evidence that individual participation in stress management strategies alone was insufficient to enhance occupational self-efficacy, whereas a combination of individual and 
highly shared participation would facilitate social and reciprocal support in facing job stress [23].

In conclusion, the evidence reviewed here indicates that the theoretical notion of shared identity is consistent with the group level-focus as the primary unit of psychological analysis of stress from a social identity perspective.

\section{Identity and Change in Organizations}

The social identity approach has also been applied to organizational change for over two decades now with a focus on research on the impact of mergers and acquisitions (M\&As) on employees' identities. Most of this research has looked at employees' individual levels of identification with pre- and/or post-merger organizations as outcome and/or predictor of their attitudes and behavior related to the M\&A success. Sung and colleagues, for instance, studied the links between organizational identification and post-merger performance of 599 employees whose organizations were engaged in M\&A activity and found that increases in organizational identification were related to increases in job satisfaction and the intention to stay in the organization, which finally had an influence on merger success [24]. Although this and several similar studies provide interesting insights in the relation between organizational change and employee identities, the issue of whether such identities are experienced as shared reality of the organizational world is not normally addressed [25].

Shared identities as a relevant factor for change success have been considered in qualitative studies. One study, for instance, found that the sharedness of identities played an important role for successful post-merger integration and the authors proposed that positive, shared identities can be achieved by focusing on employees' satisfaction with first task and second human integration [26], which is in line with Haslam's notion that building a shared social identity in M\&As helps reducing conflicts between employees and cope with M\&Arelated stressors $[2,27,28 *]$. 
In terms of intragroup and intergroup dynamics in mergers and acquisitions, LupinaWegener and colleagues defined optimal shared identity (OSI) as the employees' shared belonging to the post-merger organization in the face of salient outgroups $[29,30]$. In a qualitative study, they found such an OSI to be positively associated with work-related outcomes in the post-merger subsidiary through providing sufficient internal assimilation [31]. Shared identities can also help to increase the efficiency of transferring practices from one organization to the other after acquisition. In one study, for instance, employees were more active in transferring practices to post-merger units when they shared the values and the beliefs of the company embodied in the practice that was being transferred [31].

But how are such shared identities created? A process model of organizational identity change during a major change event such as an M\&A was proposed by Clark and colleagues [32*] who found a transitional identity in the early period of the M\&As, which could be seen as an interim identity held by employees about what their organizations were becoming. Subsequently, this transitional identity helped employees suspend their pre-merger identity and to work towards creating a new, shared identity [32].

Another important route to create a shared identity during organizational change initiatives is granting employees a sense of "continuity for the bright organization future" $\left[33^{*}, 34\right]$. Based on interviews with top managers, Ullrich and colleagues found that stability perceived by employees was of utmost importance at times of major organizational change such as an acquisition. They argued that M\&As often failed because the change was designed in ways that discontinued the old from the new identities and proposed a model in which a sense of continuity was leading to the positive transfer of pre-merger to post-merger identities by first providing observable continuity (e.g., "my job is still the same") but more importantly projected continuity as a shared identity created by organizational leaders ("I can see where we are going from here and where we will be in 5 years from now") [33]. 
Besides such mostly qualitative accounts for the importance of shared identities, there is also some evidence from the laboratory. In one study, different merger patterns were manipulated by having students work together in groups with different colors in the first phase and then bringing them together with members from a differently colored group in conditions of different representations of their "old" color with those of the new group. A pattern of integration-equality was seen as more legitimate than a merger pattern of assimilation so that a new, shared identity could be created [35].

\section{Conclusions}

We have shown that employees who strongly identify with teams or organizations experience less stress and higher well-being and that organizational change initiatives are more successful when their impact on the affected employees' identities was considered and managed. However, little of this research has looked into the effects of shared identities. There is evidence for the positive effects of shared identities on coping with stress from the laboratory [36], or indirect evidence from a meta-analysis [14]. We distinguished between identification and identities. Traditionally, identification occurs when individuals accept a significant other's goals and standards for them as their own goals and standards and selfregulate in terms of them. The significant other for employees can be a team, the organization as a whole (e.g., the mission statement), or upper management. What happens in organizations, as in families, is that the interests of the individual employees and the interests of their organization can become the same-the employee accepts the interests of the organization as his or her own. In this case, there is value congruence or goal congruence and the employees accept as their own what is expected of them. In contrast, sharing an organizational identity with others could be coordinating with others in a team effort and representing the team effort as what "we" are doing. It is not about "you" as a personal individual but "you" as a member of the team with responsibilities to the team. For some 
individuals, working in a particular company can be a central identity and they will express or display this social identity, this in-group membership, to others. We would like to highlight that both individual employees' organizational identification and shared organizational identities are shared realities [4]. Organizational identification involves shared goals and standards - having shared interests and concerns about what matters which corresponds to Higgins' Phase 3 of the development of shared reality in childhood [37]. Organizational social identities, on the other hand, are shared realities about each team member's responsibility to the team, their contribution to the "we" in-group effort—having shared beliefs about what it means to be a team member which occurs in Phase 4 of shared reality development [37]. They are shared realities because they involve the experience of having in common beliefs and concerns about what is important to the organization and about who "we" are [38].

In the area of change, we reviewed evidence from mostly qualitative studies. Future research should also use such qualitative approaches in the exploration of the relations between identity and stress to get closer insights into what shared identities actually mean to employees and which exact role emergent norms play in interpreting and dealing with stressful working conditions. On the other hand, we strongly suggest a more systematic consideration of shared identities in quantitative research. For instance, team-based studies in organizations are needed that simultaneously look at the effects of individual identification and "team identification" as a measure of sharedness. Such team or group identification should, however, not only aggregate the individual responses to the classic identification items $[39,40]$, but also develop items specifically addressing sharedness (e.g., "In our team agree on what is central to our identity"; "Team members have a high degree of overlap in their feelings of being a group member"). Multilevel models could then examine the interplay between individual identification, aggregated team (or organizational) identification and such new operationalizations of identity sharedness also incorporating other forms of identification 
such as ambivalent or disidentification $[41,42,43]$ and to test for shared beliefs with respect to these.

Finally, based on the positive relations between identification and coping with change and stress, the social identity approach can also been used to devise practical strategies. This has indeed been successfully done recently with programs to help both individuals to better utilize their group memberships [44] and organizations to create strong identities [45, 46].

\section{Conflict of interest statement}

Nothing declared.

\section{References and recommended reading \\ * of special interest}

[1] Robbins SP, Judge TA: Organizational Behavior (15 th ed.). Pearson, 2013.

[2]* Haslam SA: Psychology in organizations ( $2^{\text {nd }}$ ed.). Sage, 2004.

This excellent text provides a comprehensive overview of traditional approachs to management and compares it to the social identity approach in a wide range of organizational topics such as leadership, communication, conflict, motivation, or performance.

[3]* Lee ES, Park TY, Koo B: Identifying organizational identification as a basis for attitudes and behaviors: A meta-analytic review. Psychol Bull 2015, 141: 10491080.

This is the most comprehensive meta-analysis on the relations between organizational identification and work-related attitudes and behaviors, including performance. It also considers cultural influences and shows that the effects of identification, although substantial in individualistic societies, are even stronger in collectivistic cultures.

[4] Echterhoff G, Higgis ET, Levine JM: Shared Reality: Experiencing Commonality with others' Inner States about the World. Perspect Psychol Sci 2009, 4: 496-521.

[5] Scheepers D, Derks B: Revisiting social identity theory from a neuroscience perspective. Curr Opin Psych 2016, 11: 74-78.

[6] Tajfel H, Billig MG, Bundy RP, Flament C: Social categorization and intergroup behaviour. Eur J Soc Psychol 1971, 1: 149-178.

[7] Tajfel H, Turner JC: An integrative theory of intergroup conflict. In The Social Psychology of Intergroup Relations. Edited by Austin WG, Worchel S. Brooks/Cole; 1979: 33-47.

[8] Turner JC, Hogg MA, Oakes PJ, Reicher SD, Wetherell MS: Rediscovering the social group: A self-categorization theory. Blackwell, 1987.

[9] Haslam SA, Oakes PJ, Reynolds KJ, Turner JC: Social identity salience and the emergence of stereotype consensus. Pers Soc Psychol Bull 1999, 25: 809-818. 
[10] Van Dick R, Haslam SA: Stress and well-being in the workplace: Support for key propositions from the social identity approach. In The social cure: Identity, health, and well-being. Edited by Jetten J, Haslam C, Haslam SA. Psychology Press. 2012: 175-194.

[11] Haslam SA, Van Dick R: A social identity analysis of organizational wellbeing. In Social psychology and organizations. Edited by De Cremer D, Van Dick R, Murnighan K. Taylor \& Francis; 2011:325-352.

[12] Avanzi L, Schuh S, Fraccaroli F, van Dick R: Why does organizational identification relate to reduced employee burnout? The mediating influence of social support and collective efficacy. Work Stress 2015, 29:1-10.

[13] Giessner SR, Horton KE, Humborstad SIW: Identity management during organizational mergers: Empirical insights and practical advice. Soc Issues Policy Rev 2016, 10:47-81.

[14] * Steffens NK, Haslam SA, Schuh SC, Jetten J, van Dick R: A meta-analytic review of social identification and health in organizational contexts. Pers Soc Psychol Rev 2017, 21: 305-335.

This recent meta-analysis based on over 60 studies revealed positive associations between identification and health, both considering team and organizational identification. The relationship is stronger for indicators of the presence of well-being than absence of stress and for psychological than physical health indicators.

[15] * Horton KE, McClelland CR, Griffin MA: Defined by our hierarchy? How hierarchical positions shape our identifications and well-being at work. Hum Relat 2014, 67:1167-1188.

This study revealed that individuals in operational positions identify strongly with their career and functional workgroups and that these attachments are important in predicting their affective well-being.

[16] Wegge J, Van Dick R, Fisher GK, Wecking C, Moltzen K. Work motivation, organisational identification, and well-being in call centre work. Work Stress 2006, 20:60-83.

This study found that organizational identification was an independent predictor of job satisfaction, turnover intentions, $O C B$, and well-being, and that highly identified employees reported higher work motivation and more well-being.

[17] * Häusser JA, Kattenstroth, M, van Dick R, Mojzisch A: "We" are not stressed: Social identity in groups buffers neuroendocrine stress reactions. $J$ Exp Soc Psychol 2012, 48:973-977.

This study provided a first experimental evidence for the idea that being part of a group buffers neuroendocrine stress only if group members develop a sense of shared social identity.

[18] Frisch JU, Häusser JA, Van Dick R, Mojzisch A: Making support work: The interplay between social support and social identity. J Exp Soc Psychol 2014, 55: 154-161.

[19] * Reicher SD, Haslam SA. Tyranny revisited: Groups, psychological well-being and the health of societies. Psychologist 2006, 19:146-150.

This paper presents an experimental case study that examined the consequences of randomly dividing men into groups of prisoners and guards. This study showed that the inability to impose one's will on others leads to a decrease in group identification and to rising levels of depression, burnout and internal dissent over time, because a shared group identity provides the power that enables people to implement their beliefs and values.

[20] Haslam SA, Reicher S: Stressing the group: social identity and the unfolding dynamics of responses to stress. J Appl Psychol 2006, 91:1037-1052. 
[21] * Khan SS, Hopkins N, Reicher S, Tewari S, Srinivasan N, Stevenson C: Shared identity predicts enhanced health at a mass gathering. Group Process Intergroup Relat 2015, 18:504-522.

This study showed that identifying with a group can positively impact group members' health, and this trajectory was predicted by data concerning pilgrims' perceptions of a shared identity with other pilgrims at a mass gathering event. A shared identity amongst pilgrims had an indirect effect on changes in self-assessed health via the belief one had closer relations with one's fellow pilgrims.

[22] * Stevenson C, Sagherian-Dickey T. Collectively coping with contact: The role of intragroup support in dealing with the challenges of intergroup mixing in residential contexts. Br J Soc Psychol 2016, 55:681-699.

This is a qualitative interview study of Catholic and Protestant new residents of increasingly mixed areas of Belfast city. The paper showed how 'social cure' processes can help cope with the stress of intergroup contact. Results highlight that a shared identity enabled people to deal with unexpected intergroup threats and provided resilience to future sectarian division. [23] Füllemann D, Jenny GJ, Brauchli R, Bauer GF: The key role of shared participation in changing occupational self-efficacy through stress management courses. $J$ Occup Organ Psychol 2015, 88: 490-510.

This paper uses social identity theory as a post-hoc explanation for the effect of combining individual and shared participation in occupational stress management courses. Results revealed that only the combination of both influenced the change in occupational selfefficacy.

[24] Sung W, Woehler M, Fagan J, Grosser T, Floyd T, Labianca G. Individuals' Responses to Organizational Mergers: Pathways to Organizational Identification and Attachment. J Appl Psychol (in press).

The recent study tested the links between change, identification, and employee satisfaction and developed an integrative model showing that change in organizational identification during the merger mediates the relationship between change in personal status and organizational valence and change in attachment but also a direct relationship between change in personal valence and attachment.

[25] Drzensky F, van Dick R: Organizational identification and organizational change. In The psychology of organizational change. Edited by Oreg S, Michel A, Todnem By R. Cambridge University Press, 2013: 275-297.

[26] Birkinshaw J, Bresman H, Håkanson L: Managing the post-acquisition integration process: How the human iintegration and task integration processes interact to foster value creation. J Manage Stud 2000, 37:395-425.

[27] Hinds PJ, Mortensen M: Understanding Conflict in Geographically Distributed

Teams: The Moderating Effects of Shared Identity, Shared Context, and Spontaneous Communication. Organ Sci 2005, 16:290-307.

The authors found that shared identity moderated the effect of distribution on interpersonal conflict and that shared context moderated the effect of distribution on task conflict.

[28] * Mortensen M, Hinds PJ: Conflict and Shared Identity in Geographically Distributed Teams. Int J Confl Manage 2001, 12:212-238.

This study shows that shared identity was associated with less task conflict within distributed, but not collocated teams and might help distributed teams to better manage conflict.

[29] Lupina-Wegener A, Schneider SC, Van Dick R: The role of outgroups in constructing a shared identity: a longitudinal study of a subsidiary merger in

Mexico. Manage Int Rev 2015, 55(5):677-705.

The authors defined optimal shared identity as the members' shared belonging to the postmerger organization in the face of salient outgroups. Optimal shared identity is beneficial to 
positive work related outcomes in the post-merger subsidiary through providing sufficient internal assimilation deindividuation within post-merger subsidiary.

[30] Lupina-Wegener A, Van Dick R: Multiple shared identities in cross-border M\&As. In Mergers and Acquisitions in Practice. Edited by Tarba SY, Cooper C, Sarala RM, Ahammad MF. Routledge; 2017:182-198.

[31] Kostova T: Transnational transfer of strategic organizational practices: A contextual perspective. Acad Manage Rev 1999, 24:308-324.

[32] * Clark SM, Gioia DA, Ketchen JD, Thomas JB: Transitional identity as a facilitator of organizational identity change during a merger. Admin Sci Quart 2010, 55:397438.

The paper studied the processes of organizational identity change during the initial phases of a merger using a grounded theory approach and found that a transitional identity was critical to moving the change process forward.

[33] * Ulrich J, Wieseke J, Van Dick R: Continuity and change in mergers and acquisitions: A social identity case study of a German industrial merger. $J$ Manage Stud 2005, 42:1549-1569.

The paper examines the role of a sense of continuity for organizational identification after $M \& A s$ and shows that changes $(M \& A s)$ designed in discontinuous ways might cause failure in $M \& A s$ case. Since the way engenders a critical tension between positive and negative effects of identification.

[34] Lupina-Wegener A, Drzensky F, Ullrich J, Van Dick R: Focusing on the bright tomorrow? A longitudinal study of organizational identification and projected continuity in a corporate merger. Br J Soc Psychol 2014, 53:752-772.

[35] Giessner SR, Tendayi Viki G, Otten S, Terry DJ, Tauber S: The challenge of merging: Merger patterns, premerger status, and merger support. Pers Soc Psychol Bull 2006, 32:339-352.

This laboratory study shows that pre-merger status and merger patterns are important for employees' support to the merger. The low-status group favors integration-equality and transformation whereas the high-status group prefers integration-proportionality and assimilation.

[36] Frisch JU, Häusser JA, Van Dick R, Mojzisch A: The social dimension of stress: Experimental manipulations of social support and social identity in the Trier Social Stress Test. J Vis Exp 2015, 105:e53101

[37] Higgis ET: Shared-Reality development in Childhood. Perspect Psychol Sci 2016, 11: 466-495.

[38] Echterhoff G, Higgis ET: Creating shared reality in interpersonal and intergroup communication: The role of epistemic processes and their interplay. Eur Rev Soc Psychol 2016, 28: 175-226.

[39] Postmes T, Haslam SA, Jans L: A single-item measure of social identification: Reliability, validity and utility. Br J Soc Psychol 2013, 52: 597-617.

[40] Escartin J, Ullrich J, Zapf D, Schlüter E, Van Dick R: Individual and group level effects of social identification on workplace bullying. Eur J Work Organ Psychol 2013, 22:182-193.

[41] Kreiner GE, Ashforth BE: Evidence toward an expanded model of organizational identification. J Org Behav 2004, 25: 1-27.

[42] Van Dick R: Organizational identification. In Handbook of Employee Commitment Edited by Meyer J. Edward Elgar Publikation; 2016:106-118.

[43] Van Dick R, Haslam SA: Organizational identification. In Encyclopedia of Management Theory. Edited by Kessler EH. Sage Publication; 2013:2:556-559. 
[44] Haslam C, Cruwys T, Haslam SA, Dingle G, Chang MX-L: Groups 4 Health:

Evidence that a social-identity intervention that builds and strengthens social group membership improves mental health. J Affect Disord 2016: 194: 188-195.

[45] Haslam SA, Steffens, NK, Peters K, Boyce RA, Mallett CJ, Fransen K: A social identity approach to leadership development: The 5R program. J Pers Psychol (in press).

[46] Peters K, Haslam SA, Ryan MK, Fonseca M: Working with subgroup identities to build organizational identification and support for organizational strategy: A test of the ASPIRe model. GOM 2012, 38: 128-144. 